
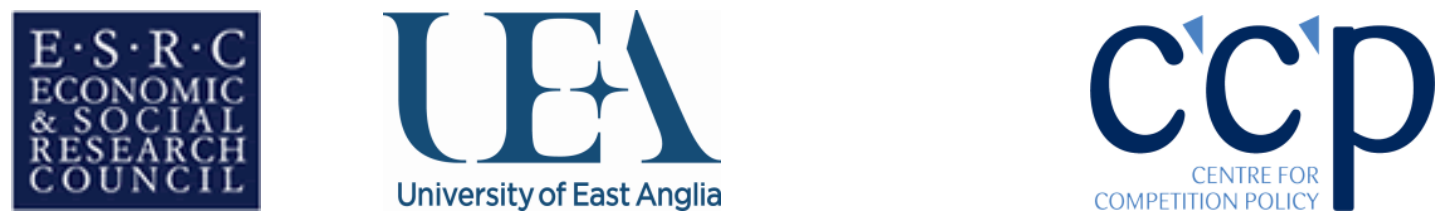

\title{
The determinants of merger litigation \\ strategies: An empirical analysis of EC
}

mergers

\author{
Peter Ormosi
}

\section{CCP Working Paper 10-1}

\begin{abstract}
Mergers with anticompetitive effects can gain regulatory approval if they prove that the benefits of the merger outweigh the negative effects (efficiency defence), and/or if they offer to modify the merger transaction in a way that eliminates these adverse effects (merger remedy). Although these two merger control instruments have been analysed separately, little work has been dedicated to modelling merger litigation where both the provision of efficiency-related evidence and remedy-offers are at the merging firms discretion, which is the case for example in the EC. This paper is an attempt to fill the empirical part of this gap. Its novelty lies not only in empirically modelling the system of decisions that firms face in merger litigation but in using data from company reports on the merger-generated synergy expectations signalled to shareholders, which allows the direct empirical testing of some of the assumptions and findings from previous works.

Evidence is presented that firms' own efficiency expectations do not have an impact on the probability of applying for efficiency defence; that pre-merger synergy expectations enhance the willingness to offer remedies; false efficiency claims can be distinguished by looking at the timing of the remedyoffer; and finally, the cost of delay plays a central role in designing firms' litigation strategy, especially when these costs exceed the cost of the remedy.
\end{abstract}

Acknowledgements: I would like to thank Catherine Ball, Morten Hviid, the participants of CCP seminar series, and the participants of the 2008 ACLE Workshop on EC Competition Enforcement Data for the valuable comments. All remaining errors are mine. The usual disclaimer applies. The support of 
the Economic and Social Research Council and the Centre for Competition Policy is also gratefully acknowledged.

Contact Details:

Peter Ormosi, Norwich Business School and ESRC Centre for Competition Policy, University of East Anglia, email p.ormosi@uea.ac.uk 


\title{
The determinants of merger litigation strategies: An empirical analysis of EC mergers*
}

\author{
Peter L. Ormosi ${ }^{\dagger}$
}

May 25, 2011

\begin{abstract}
Mergers with anticompetitive effects can gain regulatory approval if they prove that the benefits of the merger outweigh the negative effects (efficiency defence), and/or if they offer to modify the merger transaction in a way that eliminates these adverse effects (merger remedy). Although these two merger control instruments have been analysed separately, little work has been dedicated to modelling merger litigation where both the provision of efficiencyrelated evidence and remedy-offers are at the merging firms discretion, which is the case for example in the EC. This paper is an attempt to fill the empirical part of this gap. Its novelty lies not only in empirically modelling the system of decisions that firms face in merger litigation but in using data from company reports on the merger-generated synergy expectations signalled to shareholders, which allows the direct empirical testing of some of the assumptions and findings from previous works. Evidence is presented that firms' own efficiency
\end{abstract}

*I would like to thank Catherine Ball, Morten Hviid, the participants of CCP Seminar Series, and the participants of the 2008 ACLE Workshop on EC Competition Enforcement Data for the valuable comments. All remaining errors are mine. The usual disclaimer applies. The support of the Economic and Social Research Council and the Centre for Competition Policy is also gratefully acknowledged.

${ }^{\dagger}$ Norwich Business School and ESRC Centre for Competition Policy, University of East Anglia, email: p.ormosi@uea.ac.uk 
expectations do not have an impact on the probability of applying for efficiency defence; that pre-merger synergy expectations enhance the willingness to offer remedies; false efficiency claims can be distinguished by looking at the timing of the remedy-offer; and finally, the cost of delay plays a central role in designing firms' litigation strategy, especially when these costs exceed the cost of the remedy. 


\section{Introduction}

Merger control is focused on governing mergers that hinder competition and are large enough for this effect to be harmful for the society. The competition authority (CA) investigates these mergers and, if evidence is found of the anti-competitive effects, prohibits them. When determining the competitive impact of a merger, the CA takes into account expected efficiencies put forward by the merging firms (efficiency defence). The efficiencies brought about by the merger can counteract the negative effects on competition and the potential harm to consumers. If these efficiencies are sufficient enough to outweigh the anticompetitive effects, the CA will approve the merger. In the absence of efficiency gains, anticompetitive mergers may also receive regulatory approval if parties to the merger offer a settlement package (merger remedy) to the $\mathrm{CA}$, which modifies the notified merger transaction, as a result of which the anticompetitive effects are eliminated.

The common factor in the above two legal instruments (merger remedies and efficiency defence) in many jurisdictions is that they both have to be initiated by the merging parties. The $\mathrm{CA}$ is not in the position to impose remedies on the merging parties, but it can assess whether the remedies are capable of eliminating the competition problem. Similar rules apply to efficiency claims. Given the information asymmetry between the CA and the merging firms, the CA only takes those substantiated and likely efficiencies into account that were brought forward by the merging parties. Merging firms' litigation strategy may therefore take three main forms: offer a settlement, provide evidence on efficiencies, or do both.

There is an ever increasing body of literature that has developped ways to theoretically model merger litigation but only a few of them addresses the possible interaction between the above two merger control instruments. To mention some of the most recent works, papers by Lagerlöf and Heidhues (2005), Motta and Vasconcelos (2005), or Neven and Röller (2005) model merger litigation with a special focus on efficiency claims. Garrod and Lyons (2011) on the other hand focus more on the analysis of remedy-offers in litigation. Some papers however depict merger litigation where both efficiency claims and remedy-offers simultaneously exist and interaction 
between the two is allowed. For example Cosnita and Tropeano (2009) propose a solution to overcoming the difficulties arising from the information asymmetry between the CA and merging firms by providing a mechanism that extracts efficiency-related information from the merging parties. They suggest that efficient mergers value their assets higher and are therefore less willing to divest them. Bougette (2010), who analyses the effectiveness of remedies, also found that cost savings reduce the scope of remedies. ${ }^{1}$

This paper is an attempt to model merger litigation empirically by looking at how firms design their litigation strategy, of which efficiency claims and remedyoffers both form part. Its novelty lies not only in empirically modelling the system of decisions that firms face in merger litigation but in using data from company reports on the merger-generated synergy expectations signalled to shareholders. This allows the direct empirical testing of some of the assumptions and findings from previous works.

Although the focus of analysis is on European Community mergers, the findings of this paper should bear relevance to all jurisdictions that place both remedy offers and efficiency defence at the merging parties' discretion.

The paper presents some evidence that firms' expectations on merger-generated efficiencies do not determine whether they make efficiency claims before the CA. This is evidence against assumptions that mergers with efficiency evidence in hand always have the incentive to reveal this evidence, something that is used for example in Motta and Vasconcelos (2005), Neven and Röller (2005), or CT. Rather, some mergers with relevant evidence may decide to keep quiet about it, potentially for reasons discussed in $\mathrm{LH}^{2}$ At the same time, other mergers that have no efficiencyrelated evidence may try to bluff and make efficiency claims.

Both CT and Bougette (2010) claim that cost savings reduce the willingness to

\footnotetext{
${ }^{1}$ For the repetitive referencing to the Lagerlof and Heidhues (2005), the Cosnita and Tropeano (2009), and the Garrod and Lyons (2011) papers, they are hereinafter denoted as LH, CT, and GL respectively.

${ }^{2} \mathrm{LH}$ argue that by choosing the enforcement regime (laissez-faire, hard-evidence, or strict regime) CAs can influence the amount of evidence merging firms provide on efficiencies. A strict regime never allows for efficiency defence, a lasses-fair regime always approves mergers, and a hard-evidence regime requires strong efficiency-related evidence.
} 
offer a divestiture. Although this paper only makes inferences on the size of divestitures relative to the level required by the $\mathrm{CA}$, evidence is presented that firms only exhibit reluctance to offer large upfront remedies when they made efficiency claims to the CA (bluffing or genuine claims). When they choose to withhold efficiencyrelated evidence they become more eager to find an early settlement and this effect becomes stronger the more efficiencies they signalled to shareholders. One possible explanation to this could be that given the higher saving expectations, these mergers are expected to be more delay-averse (higher cost of delay) and are therefore likely to be offering overly large remedies to gain early approval, as proposed by GL.

Finally, evidence is provided on the phenomenon that mergers with higher efficiency expectations - i.e. more delay-averse mergers - are willing to reach early settlement by making larger and quicker remedy-offers except when they made efficiency claims to the Commission. This implies that firms may have an expectation of tailoring remedies to take the total effect of mergers (including efficiency gains) into account, the importance of which has been highlighted by Röller and de la Mano (2006).

The paper is structured as follows. First, the motivation is given together with a set of testable hypotheses, which stem from preliminarily observed data, the characteristics of the EC merger control regime, and the priors brought from theoretical papers. This is followed by a model of the system of decisions in merger litigation. The data and the key variables are then introduced, followed by a discussion of the exogeneity of these variables and potential selection bias issues. Based on the assumptions and the chosen model, a set of estimates are presented and their economic interpretation is discussed. The paper concludes with an analysis of the robustness of the results to the assumptions made.

\section{Motivation of the paper and testable hypotheses}

The motivation of this paper came from the preliminary results of a research into the synergies signalled to shareholders by EC merging firms pre-merger. Figure 1 plots the number of cases with such signals and compares it to the number of times 
Figure 1: Number of cases with efficiency expectations (1999-2009)

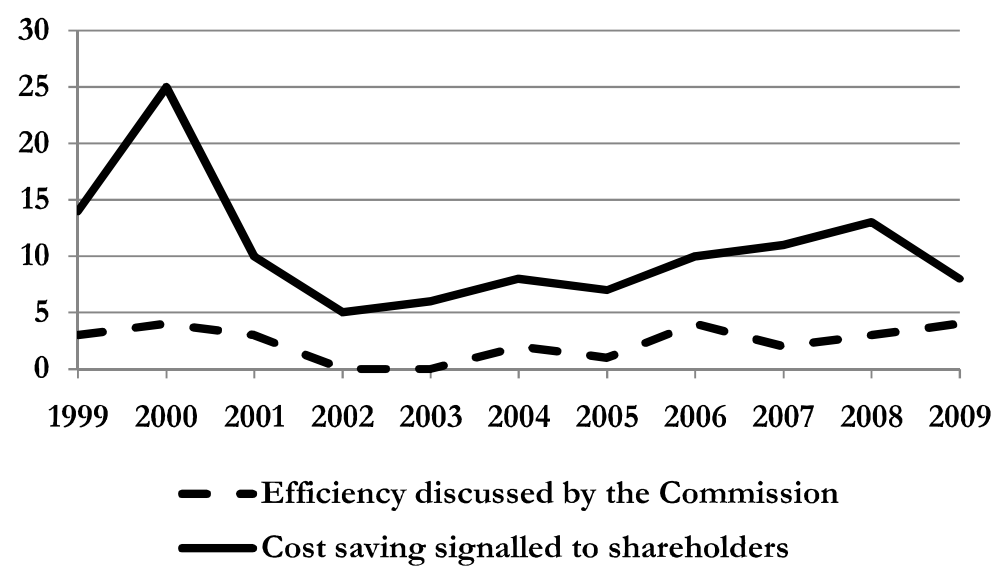

these saving expectations were revealed to the Commission.

It appears that only a fraction of the saving expectations are revealed to the Commission. This is even more remarkable knowing that the merger process starts much before it is notified to the competition authority. Clean teams build detailed financial models for assessing cost synergies arising from the merger, usually broken down to production levels or even to units. ${ }^{3}$ They provide monitoring instruments for tracking synergies, advice lawyers on regulatory issues, and set up the postmerger governance model. ${ }^{4}$ This is often a result of months of rather costly work of clean teams, and in-house experts, who are paid even if the merger does not need a regulatory authorisation. With this information in hand, no extra direct costs are incurred by bringing this evidence forward to the Commission, and one would thus expect that many mergers will do so. However, the Commission's case law suggests that efficiency claims take a long time to investigate and can typically only be done in frame of a lengthy second phase investigation. ${ }^{5}$ This potential delay represents

\footnotetext{
${ }^{3}$ As the pre-merger cooperation or coordination of firms would trigger the intervention of anticartel agencies, merging parties often hire clean teams to design an effective integration strategy. Clean teams carry the mandate of the merging parties and have legal clearance to analyse any relevant company data and work under strict confidentiality.

${ }^{4}$ See more on clean teams in Chanmugam et al. (2005).

${ }^{5}$ Ormosi (2011) provides a summary of these effects.
} 
extra costs for the merging parties. These two effects (having the evidence in hand, and facing the prospect of a delay as a result of providing this evidence) should, in theory, simultaneously determine how much efficiency-related evidence firms reveal to the CA.

Although LH provide a framework for analysing how the CA's behaviour influences this decision, it is uncertain how their results would impact remedy offers in a scenario that allows for the fact that merger approval can also be gained by offering a suitable set of remedies. The main driver of my research was to find the determinants of this complex choice in a setting where efficiency evidence and remedy offers can both lead to approval.

\subsection{The regulatory framework}

In order to understand how the obstruction of evidence may be of firms' interest some understanding of the underlying legal system is needed. When firms decide to merge, they know whether their transaction will be subject to regulatory approval. As litigation can reduce shareholder wealth, it is assumed that firms have an interest in avoiding it, or - if inevitable - seek some type of settlement as quickly as possible.

According to the European Merger Regulation, ${ }^{6}$ an otherwise anti-competitive merger can be approved only if the benefits arising from the merger outweigh the negative effects, but the burden of proof is on the merging parties. ${ }^{7}$ This would suggest that withholding information on the benefits makes very little sense. However, the assessment of efficiencies is very likely to trigger a lengthy investigation, ${ }^{8}$ which has been clearly pronounced out by the Commission in previous cases. ${ }^{9}$ These proceedings typically last for about 6 months thereby not only increasing the costs

\footnotetext{
${ }^{6}$ Council Regulation (EC) No 139/2004 of 20 January 2004 on the control of concentrations between undertakings (OJ L 24, 29.01.2004, p. 1-22) (hereinafter referred to as: the new ECMR).

${ }^{7}$ See Paragraph 87 of the Horizontal Merger Guidelines.

${ }^{8}$ In the context of European merger control the Commission appraises the notified merger before deciding on whether to initiate proceedings. If it can be concluded from available evidence that the merger does not raise serious doubts as to its compatibility with the common market, or if there are doubts but they are eliminated by the modifications offered by the merging parties the Commission may approve the merger without initiating proceedings.

${ }^{9}$ See for example Paragraph 62, Case No IV/M.4057 - Korsne/Assidomd Cartonboard (2006).
} 
arising from delay but also the uncertainty surrounding the approval of the merger, which may negatively influence the shareholder valuation of the merging firms. ${ }^{10}$

Given this environment it is crucial that merging parties also have the possibility of agreeing on some sort of settlement with the competition authority, which modifies the original transaction and remedies the anti-competitive effects of the merger, for example by divesting some of their assets. This of course comes at the cost of losing the divested assets. ${ }^{11}$ This is made even more complex given that the perceived cost of this divestiture potentially increases with the shareholder valuation of the transaction. $^{12}$

This means, that in merger jurisdictions such as the EC, when seeking approval, firms have to balance between the cost of divesting valuable assets, and the cost of a delay caused by the regulatory assessment of efficiencies. For this reason, if the cost of delay is higher than the cost of divestiture, evidence on efficiencies may be withheld during the investigation. If delay is less costly than divestiture, firms are expected to reveal efficiency evidence and offer only smaller remedies.

Figure 2 presents a stylised flowchart depicting the two main elements of merger litigation that the merging parties have to address when notifying an anticompetitive merger: (1) whether to reveal efficiency-related evidence; and (2a) how large a modification to offer, and (2b) when to make the offer.

The first decision that merging parties have to make is whether to bring forward efficiency-related evidence or not (conditional on the merger generating such efficiencies). Firms can always bluff and claim efficiencies even if they themselves are not counting on them. Although the ECMR does not set a time limit for efficiency

\footnotetext{
${ }^{10}$ Speed is one of the key constituents of a successful merger integration process. Delay can jeopardise the success of integration in various ways, for example by losing out to a rival preemptive bid. Delay can also threaten the success of merger-generated synergies. Epstein (2004) points out some other threats, for example that employees and customers may regard the slow pace of integration as a sign of uncertainty and may pursue opportunities at rival firms.

${ }^{11}$ In reality this is probably a lot more subtle, as evidence shows that settlements - or the anticipation of settlements - in lawsuits increase shareholder wealth. See for example Fields (1990), Koku and Qureshi (2006), Bhagat et al. (1994), or for a comprehensive meta-study, Bhagat and Romano (2002).

${ }^{12}$ For example, as CT claim, more efficient mergers value their assets higher and are therefore less willing to divest them.
} 
Figure 2: A stylised flowchart of the litigation strategy of parties in anticompetitive mergers

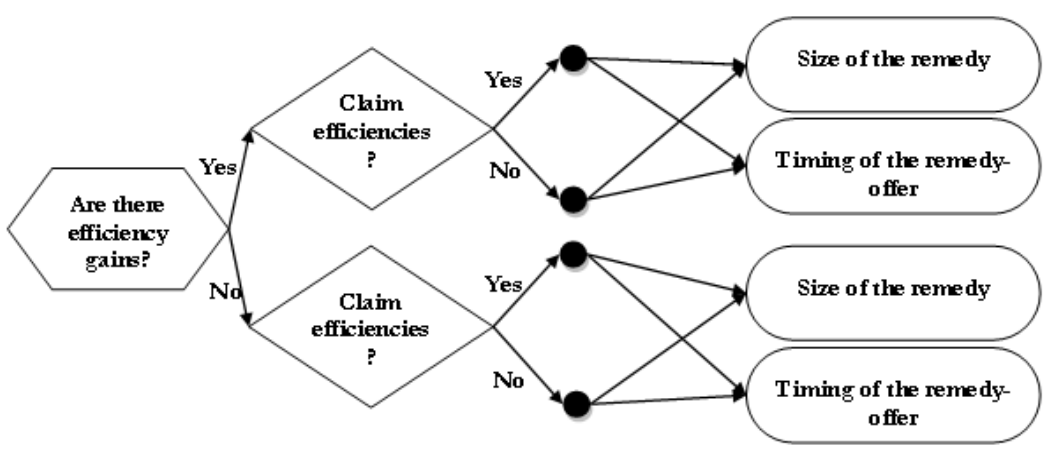

claims, the Commission recommends that parties reveal them as early as possible, even in the pre-notification phase. ${ }^{13}$ This means that merging parties must have a clear idea whether to disclose efficiency-related evidence to the Commission already at the pre-notification level. This is important for the empirical model presented below as it suggests that firms' decision on efficiency evidence and remedy-offers are a sequential process.

On the second level of the flow chart, parties make remedy-offers. Although under the ECMR merging parties would be free not to offer remedies after revealing efficiency claims to the Commission, in the Commission's case law anticompetitive mergers have never been approved without suitable remedies based on efficiency arguments only. ${ }^{14}$ If remedies are not offered, the Commission prohibits the merger,

\footnotetext{
${ }^{13}$ The pre-notification phase is an informal stage of EC merger procedures, to discuss jurisdictional and other legal issues. The Commission recommends these discussions to start at least two weeks prior to notification (Paragraph 10 of the DG COMPETITION Best Practices on the conduct of EC merger control proceedings).

${ }^{14}$ There are cases - not in the analysed sample - where the parties revealed merger-specific efficiencies and eventually no intervention was needed but it is very difficult to decide how much weight efficiencies had in convincing the Commission that the merger was harmless. Efficiencies in these cases were considered to be one of several factors outweighing anticompetitive effects arising from the transaction but not as the single or exclusive factor. Factors such as the existence of significant buying power, increased competition from outside the EEA, or finding that the merging parties are not each other's closest competitors (see for example paragraphs 57-64 in COMP/M.4057, Korsnäs/AssiDomän Cartonboard). These decisions also suggest that in the given cases the com-
} 
unless the merging parties withdraw their case beforehand. ${ }^{15}$ It is therefore assumed that remedies are offered in all mergers with anticompetitive effects and firms only have to decide when to make the offer to modify the merger and how large a modification to offer, conditional on the decision made on revealing efficiency related evidence. Although logically, the remedies offered should be smaller if efficiencies have also been claimed, the Commission's practice suggests that remedies are not weighted against potential efficiency gains, which was highlighted by Ormosi (2011). If the merging parties take this into consideration then their remedy-offer will be the same even if efficiencies had been claimed before.

\subsection{Hypotheses}

From previous papers and given the background information described above, the following hypotheses are tested.

Hypothesis 1a: Firms engage in mixed signalling (high signals to shareholders, low signals to the regulator) before mergers are consummated. They signal high efficiencies to shareholders but they do not reveal these efficiencies to the competition authority, therefore even with the efficiency-related evidence in hand it may not be revealed to the $\mathrm{CA}$, much in the same way as proposed by $\mathrm{LH}$.

Hypothesis 1b: Firms try to capitalise on the information asymmetry between them and the regulator by claiming efficiencies even when they do not in fact expect them.

Hypothesis 1c: Even with efficieny evidence in hand firms may choose not to reveal it, therefore assumptions in Motta and Vasconcelos (2005), Neven and Röller (2005), or CT, that efficiency related evidence is always shared with the CA, may

petition concern was not particularly strong and the merger might have equally been authorised without the efficiency arguments. This is confirmed by the fact that none of these decisions contain a detailed analysis of the expected efficiencies and these mergers were approved in a phase I procedure. See also COMP/M.3732, Procter \& Gamble/Gillette, paragraph 131, COMP/M.3664, Repsol Butano/Shell Gas (LPG), paragraphs 33-35; COMP/M.3886, Aster 2/Flint Ink, paragraph 22.

${ }^{15}$ For the lack of data, withdrawal cases are not discussed in this paper. However, from the merger's perspective, prohibition and the withdrawal of the case have the same effect. 
not hold.

Hypothesis 2: When synergy expectations about a merger are high, firms seek early settlement by:

a) offering to make relatively large modifications, and/or

b) offering to modify the merger transaction early in the litigation.

These hypotheses seemingly contradict CT and Bougette (2010) who claim that high cost savings reduce the size of remedy-offers. This research however allows synergy expectations to serve as a proxy for cost of delay, which is expected to produce different results from CT, as discussed above.

Hypothesis 3: Signalling efficiency expectations to the Commission does not reduce firms' willingness to settle the case by making suitable remedy-offers. Although Röller and de la Mano (2006) suggest that CAs should tailor remedies to take efficiency gains into account, that is not how firms perceive the Commission's practice and they offer the same remedies even if efficiency related evidence is revealed.

\section{Modelling the litigation strategy of merging par- ties}

The three estimable parameters from Figure 2 are firms efficiency claims to the Commission (eff), and the two measures of firms' willingness to reach settlement: the size of the remedy-offer $\left(\mathrm{rem}_{s}\right)$ and the timing of the remedy-offer $\left(\mathrm{rem}_{t}\right) .{ }^{16}$ These could be arranged in the following unrestricted system of structural equations:

$$
\begin{aligned}
& \text { eff }=\alpha_{1} v a l+\gamma_{11} r e m_{s}+\gamma_{12} \text { rem }_{t}+\beta_{1}^{\prime} \mathbf{x}_{1}+\varepsilon_{1} \\
& r e m_{s}=\alpha_{2} v a l+\gamma_{21} e f f+\gamma_{22} r e m_{t}+\beta_{2}^{\prime} \mathbf{x}_{2}+\varepsilon_{2} \\
& r e m_{t}=\alpha_{3} v a l+\gamma_{31} e f f+\gamma_{32} r e m_{s}+\beta_{3}^{\prime} \mathbf{x}_{3}+\varepsilon_{3}
\end{aligned}
$$

\footnotetext{
${ }^{16}$ The section to follow borrows intensively from Maddala (1983, 242-7).
} 
Where val is a key exogenous variable that denotes the efficiency expectations signalled to shareholders, $\gamma_{n}$ are the coefficients of the potentially endogenous parameters, and $\varepsilon_{n}$ are the error terms, with $E\left(\varepsilon_{n}\right)=0$, and $\operatorname{Var}\left(\varepsilon_{n}\right)=\sigma^{2} . \mathbf{x}_{n}$ are vectors of exogenous variables, and $\beta_{n}$ denotes the corresponding parameters. ${ }^{17}$ From the data, the system is observed as follows:

$$
\begin{aligned}
\text { rem }_{s} & =r e m_{s}^{*} \\
\text { rem }_{t} & =r e m_{t}^{*} \\
\text { eff } & =1 \text { if } \text { eff } f^{*}>0 \\
\text { eff } & =0 \text { otherwise }
\end{aligned}
$$

Where $e f f^{*}$ is a latent variable of which the dichotomous variable eff is observed and denotes the cases where merging parties made efficiency claims to the Commission; rem $_{s}$ and rem $_{t}$ are observed.

Assumption 1: $E\left(\mathbf{x}_{n}^{\prime} \varepsilon_{n}\right)=0$ and $E\left(v a l \varepsilon_{n}\right)=0$, which is the orthogonality assumption required for $\mathbf{x}_{n}$ and val to be exogenous.

The following assumptions reduce this unrestricted system to the one estimated in this paper. These assumptions are required to decide whether all variables that are thought to be endogenous ( $\mathrm{ef} f, \mathrm{rem}_{t}, \mathrm{rem}_{s}$ ) in the model in Figure 2 should be included in Equations (1) to (3). First the relationship between eff and the other variables is considered, then $\mathrm{rem}_{s}$ and $\mathrm{rem}_{t}$ are examined separately. The robustness of the assumptions made here is discussed in the final section.

\subsection{Efficiency claims}

Assumption 2: $\gamma_{11}=\gamma_{12}=0$. This assumption formalises that there is a oneway causality between eff and $\mathrm{rem}_{s}$ or $\mathrm{rem}_{t}$, therefore firms first decide whether to reveal efficiency-related evidence, and then choose the size of the necessary remedy. If Assumptions 1 and 2 hold, then Equation (1) can be estimated using a single

\footnotetext{
${ }^{17}$ It is assumed that for all $\mathbf{x}_{n}$ there is an element of $\mathbf{x}_{n}$ that is not contained in $\mathbf{x}_{m}$, where $n \neq m$. This assumption is unnecessary if $\varepsilon_{n}$ are independent of each other.
} 
equation probit model.

When eff is a regressor in Equations (2) and (3), if $\gamma_{21} \neq 0$ and/or $\gamma_{31} \neq 0$ then the following two possibilities are possible. If $\mathrm{rem}_{s}$ and/or rem $_{t}$ are observed following some selection criterion arising from ef $f$, then Heckman's sample selection model could be used. ${ }^{18}$ Whether this is the case will be tested later. If there is no sample selection issue and the error terms are not contemporaneously correlated, then we have a recursive model with a continuous and a dichotomous variable. Methods for fitting such models are discussed in Maddala and Lee (1976, p.527), who show that, if $\varepsilon_{1}, \varepsilon_{2}, \varepsilon_{3}$ are normally distributed, Equation 1 can be estimated using probit, and Equations 2 and 3 using OLS. If $\varepsilon_{1}$ is not independent from $\varepsilon_{2}$ and/or $\varepsilon_{3}$, then Equation 1 can be estimated using probit, and Equations 2 and 3 can be estimated by replacing eff by the estimated $\Phi\left(\alpha_{1} v a l+\beta_{1}^{\prime} \mathbf{x}_{1}\right)$ and using OLS. ${ }^{19}$

Assumption 3a: $E\left(\varepsilon_{1} \varepsilon_{2}\right)=0$

Assumption 3b: $E\left(\varepsilon_{1} \varepsilon_{3}\right)=0$

These are the independence assumptions required to simplify the estimation process to a probit method for Equation 1 and a separate estimation of Equations 2 and 3 .

\subsection{Equations 2 and 3}

Assumption 4a: $\gamma_{22}=0$ and $\gamma_{33} \neq 0$

Assumption 4b: $\operatorname{corr}\left(\varepsilon_{2}, \varepsilon_{3}\right)=0$

Assumption 4a states that rem $_{s}$ affects rem $_{t}$ but not the other way round, i.e. first parties decide on the size of the offer (whether they want to bluff or not), which determines their attitude towards settlement and how early they make the offer. ${ }^{20}$ It is unlikely that firms decide when to make the offer before they know what the offer would be. If firms are delay-averse then they will offer large, and are more likely to do this early. On the other hand, if they try to bluff and start with smaller

\footnotetext{
${ }^{18}$ For an explanation see Breen (1996), and Maddala (1983).

${ }^{19}$ The calculation of variances is explained on p.529 in Maddala and Lee (1976).

${ }^{20} \mathrm{~A}$ theoretical model for this bargaining process is given in LG.
} 
offers, they might also think that early offers are preferable. To decide which effect dominates, the following hypothesis is tested:

Hypothesis 4: Firms choosing a bluffing strategy (i.e. making a small offer) to reach settlement are more likely to make early offers, thereby allowing themselves more time to adjust their offer if the Commission finds out about the bluff. This is in line with the arguments in GL, who argue that bluffing about settlement-offers is viable when delay is not very costly for the merging firms. In these cases firms would be willing to make a small remedy offer. To safeguard from the possibility of a lengthy phase II investigation, it is likely that these bluffing offers are made earlier in order to allow more time to adjust the offer in case of a failed bluff. This should also mean that rem $_{s}$ 'causes' some of the variance in $r e m_{t}$.

Assumption $4 \mathrm{~b}$ is needed for Equations (2) and (3) to be estimable using OLS.

Table 1: A summary of the estimable system, and testable hypotheses

\begin{tabular}{lll}
\hline Dependent variable & Regressor & Hypotheses \\
\hline \hline eff & $\alpha_{1} v a l+\beta_{1}^{\prime} \mathbf{x}_{1}$ & H1: $\alpha_{1}=0$ \\
\hline$r e m_{s}$ & $\alpha_{2} v a l+\gamma_{21} e f f+\beta_{2}^{\prime} \mathbf{x}_{2}$ & H2: $\alpha_{2}>0$ \\
& & H3: $\gamma_{21}=0$ \\
\hline & & H2: $\alpha_{3}<0$ \\
rem & & H3: $\gamma_{31}=0$ \\
& $\alpha_{3} v a l+\gamma_{31} e f f+\gamma_{32}$ rem $_{s}+\beta_{3}^{\prime} \mathbf{x}_{3}$ & H4: $\gamma_{32}>0$ \\
\hline
\end{tabular}

Table 1 summarises the hypotheses tested below. Assumptions 1-4 imply that single equation probit and OLS methods can be used depending on selection bias and endogeneity tests. 


\section{The data}

\subsection{The analysed mergers}

The paper looks at 11 years (1999-2009) of EC merger control. The common denominator of these cases is that they all resulted in anti-competitive effects. For this reason firms had to either provide efficiency-related evidence, or reach settlement by offering to modify the merger transaction in a way that eliminates the anti-competitive effects (or engage in both). The sampling process used for this research was purposive as it aimed at collecting all of those European Commission cases within the analysed timeframe which involved some sort of intervention from the Commission's part. The Commission's case reports and the Hearing Officer's reports (where available) were used as primary data source.

Between 1990 and 2009, 297 anticompetitive mergers were discussed under the ECRM. ${ }^{21}$ The most obvious constraint was the availability of the required data in the text of the decision. The range of available information decreases for older decisions, which resulted in cutting the sample at 1999. Another constraint was given by the availability of case reports in English or French. From the 232 cases in the examined period, twelve were in German, three in Italian, and three in Spanish, leaving 214 cases (over 70 percent of the total number of investigated mergers) to be analysed. ${ }^{22}$ There is no reason to believe that the non-English or French texts contain cases that are systematically different from the analysed sample. The analysed sample includes 116 cases under the old ECMR and 98 cases under the new ECMR. ${ }^{23}$

There was also a reporting bias from the Commission's part, due to the fact that phase I documents do not contain the same amount and level of information as phase II documents. This meant that some of the structural variables (e.g. entry characteristics, market shares outside of the relevant markets) had to be dropped,

\footnotetext{
${ }^{21} 63$ of these were in the pre-1999 era. See EC merger control statistics, available at: http://ec.europa.eu/competition/mergers/statistics.pdf

${ }^{22}$ Assuming that the 18 German, Italian and Spanish texts are a random sample of the population of intervention merger cases between 1999 and 2009.

${ }^{23}$ Council Regulation (EEC) No 4064/89 of 21 December 1989 on the control of concentrations between undertakings (OJ L 395, 30.12.1989) (hereinafter referred to as: the old ECMR).
} 
as this information was simply not reported in the phase I documents. This is also true with regards the comparison between older and more recent documents. Some information that was only reported in, say, post-2004 documents cannot be used for a credible analysis when it is obvious that the lack of information for pre-2004 documents is due to the fact that the Commission had different reporting policies.

\subsection{Potentially endogenous variables}

eff is a dichotomous variable that allows a distinction between cases where firms revealed efficiency related evidence to the Commission, and cases where they did not. Given the limited amount of efficiency-related discussion in these reports, a more ambitious measurement of efficiency claims, other than a binary variable, was not possible.

The size of the remedy was measured using a simple proxy. When remedies are offered, the Commission decides whether a received offer is sufficient to remedy the competitive concerns. $^{24}$ If the offer is turned down, then the merging parties have to find an alternative remedy that they can include in their subsequent offer. ${ }^{25}$ If the offer is accepted, the case is closed with the Commission's final decision. If no suitable offer is made by the end of the statutory deadline, then the merger is blocked. The length of time (number of working days) between the first offer and the closure of the procedure is used as a measure of the size of the first offer relative to the offer needed to eliminate all anti-competitive effects of the merger $\left(\right.$ rem $\left._{s}\right)$. A short time-period therefore indicates a large enough remedy offer to be accepted by the Commission. To facilitate interpretation, rem $_{s}$ was multiplied by minus one, therefore a higher rem $_{s}$ means a relatively larger initial offer. ${ }^{26}$

Finally, for the other element of the willingness to settle, the timing of the first remedy $\left(\mathrm{rem}_{t}\right)$ is measured by the number of working days between the notification

\footnotetext{
${ }^{24}$ See Judgment of the CFI in Case T-210/01 General Electric v Commission [2005] ECR II-0000, paragraph 52; or in Case T-87/05 EDP v Commission [2005] ECR II-0000, paragraph 105.

${ }^{25}$ See Recital 30 of the new ECMR.

${ }^{26}$ Those who struggle to accept rem $_{s}$ as a measure of relative remedy size, can think of it as a measure of willingness to settle the case by making a suitable remedy offer.
} 
of the merger, and the day the remedy was offered.

\subsection{Exogenous factors determining merging parties' litiga- tion strategy}

One of the novelties of this research is the use of data on pre-merger efficiency expectations. ${ }^{27}$ The data collected for this purpose was the quantified merger-generated saving expectations signalled to shareholders pre-merger. ${ }^{28}$ As these expectations are based on the pre-merger assessment of the effect of the merger, it is used as a measure of the efficiency-related evidence that firms have in hand before notification.

Four major sources were used for collecting this data: (1) Merging parties' annual reports: The relevant information (pre-merger synergy expectations) was found in the report of the year of the merger announcement. (2) Company press releases: These short informational articles are a brief and prompt signalling means. They are normally available on the merging parties' websites or in their online archives. (3) Business-and-law search engines such as Lexis-Nexis. (4) Google news archives were used to double-check the information acquired through the first three steps, or if the annual report was not detailed enough or simply because there was no annual report available. The data on synergy expectations was only used if there were at least three different news sources reporting the same expectation, around the same time.

To standardise the saving expectation data (i.e. to adjust for differences in firm size, and length of time needed for the savings to be realised) the present value $(p v)-$ at the time of the merger announcement - of the deflated annual cost savings (cs) was calculated. ${ }^{29}$ This is an annuity to be realised in $y$ years following the merger, and it

\footnotetext{
${ }^{27}$ Although synergy expectations were collected from the above listed sources, there have been academic attempts to measure these synergies from other available data. Chang (1988) for example proposes a method for calculating these anticipated synergies using three variables: the acquisition premium paid by the buying firm, the market value, and the replacement costs of the target firm.

${ }^{28}$ Although it has been shown that saving expectations often fall short, here they only imply merging parties' pre-merger expectations.

${ }^{29}$ Quarterly indices (for the corresponding quarter of the merger notification) from the UK Retail Price Index (RPI) were used (published on www.statistics.gov.uk) for deflation.
} 
was assumed that this annuity would last for five years in every case. ${ }^{30}$ The present value of the annuity in $y$ years following the merger is given by: $p v_{y}=\frac{c s}{0.1}-\left(\frac{c s}{0.1}\right)\left(\frac{1}{1.1^{5}}\right)$ , and the present value now is: $p v=\frac{p v_{y}}{1.1^{y}} \cdot{ }^{31}$ As larger mergers are more likely to realise larger cost savings, the calculated present value of savings was divided by the size of the transaction $(p a)$, to get: $v a l=\frac{p v}{p a}$. These saving expectations could also be thought of as the cost of delay in merger litigation. ${ }^{32}$

Information on the size of the transaction $(p a)$ was collected from the same sources as saving expectations. As the absolute size of the merger transaction should not affect how individual mergers are adjudged by the Commission, this variable is not expected to have a significant effect on parties' decisions throughout litigation. ${ }^{33}$ The value of the transaction was measured in million GBP. ${ }^{34}$

The estimated models also control for the interaction between eff and val. In these models ef $f$ can be interpreted as an efficiency claim when firms have no genuine efficiency expectations (i.e. when they bluff in their claim), val shows the impact of efficiency expectations when firms withhold efficiency-related evidence, and val $*$ eff shows the impact of these expectations where firms provide efficiency evidence to the Commission (i.e. when there is no bluffing).

The change in the merger regulation in 2004 (ecmr), which significantly reformed the way how efficiencies can be treated in merger cases, was also expected to play a role in how firms design their litigation strategy. Although the four-digit part of the Commission's case numbers (cno) has been used in other works to measure the experience of firms and that of the Commission, its correlation with ecmr makes it

\footnotetext{
${ }^{30}$ Changing this assumption does not have an effect on the findings of this paper.

${ }^{31}$ A $10 \%$ inflation rate was used for simplicity.

${ }^{32}$ As Chanmugam et al. (2005) point out, for an acquirer expecting to reap $\$ 500$ million in yearly cost savings from an M\&A transaction, a one-month delay reduces the net present value of the deal by more than $\$ 150$ million (assuming a 10 percent cost of capital). A seven-month delay costs nearly $\$ 1$ billion in lost value, or approximately $\$ 3.5$ million per day.

${ }^{33}$ Although the world-wide turnover of the merging firms - as documented in EC case reports - has been used in some empirical works to control for the size of the merger, this data is only available for around half of the cases, and observations are more likely to be missing for mergers with small pa. To my knowledge this paper is the first attempt to use the price paid for the merger transaction as a measure of the size of the transaction.

${ }^{34}$ Deflated by using the same price index as for val.
} 
an unsuitable regressor. ${ }^{35}$

Another possible determinant of the analysed entrepreneurial decisions is the complexity of the given merger. For example, a larger remedy package may be required if more horizontal overlaps are created. These remedies might be more difficult to design and thus could take more time to offer. For measuring complexity, a proxy had to be found that was equally available for all cases in the sample. The number of horizontal overlaps was found to fit this purpose, therefore one aspect of complexity was measured by the proportion of overlaps with competition concerns to the total number of merger-created overlaps (covlperc). ${ }^{36}$ Dummy variables were used to control for anticompetitive vertical (vert) and coordinated effects (coor).

The amount of time merging parties spend before notifying their merger may also affect the litigation strategy. For example a notification may be delayed as parties spend more time preparing the right remedy offer, or gathering evidence on the efficiencies created by the merger. The time spent between the announcement of the merger and notification may also serve as an indicator of cost of delay. For ease of interpretation, in the estimation a set of three categorical dummies were used to measure the number of working days between the announcement of the merger and notification: less than 2 months (startc1), 2-4 months (startc2), more than 4 months (startc3). Information on this variable was collected from the same sources as val.

Finally, the type of the remedy was included in the estimations using three binary variables: divestiture only (div), behavioural only (beh) and both (div $\left.{ }^{*} b e h\right) .{ }^{37}$ Some of the estimated models also control for industry effects, where dummy variables for industries as defined by the European Community's statistical classification of

\footnotetext{
${ }^{35}$ The case number was used to measure experience for example by GL.

${ }^{36}$ Although other papers such as Bougette and Turolla (2006), Bergman et al. (2007), or LG use pre-, and post-market shares as a measure of horizontal effects, that would require a market-based and not merger-based analysis. It is often not identifiable which markets the efficiency claims, and pre-merger efficiency expectations relate to, therefore the analysis was merger-level and not market-level. This explains the choice of the proxy for horizontal effects.

${ }^{37}$ Merger remedies are aimed at eliminating the anti-competitive effects of a merger. This can be achieved by either rearranging the structure of the industry (structural remedy or divestiture) or by directly changing the behaviour of market players by requiring them to engage in a given type of behaviour (behaviour or conduct remedy).
} 
economic activities (NACE) is used. ${ }^{38}$ The mean of these variables is presented in Table 2, broken down into cases with and without pre-merger synergy expectations.

\section{Model selection}

At first, a consistent estimation method that produces efficient estimates is found, then the estimation results are presented, which is followed by a discussion of these results.

\subsection{Testing for treatment effects}

The fundamental problem that arises from measuring the causal effect of a treatment is that treated individuals may be inherently different from untreated ones (i.e. the difference between the two groups would be more than just the fact of the treatment). When measuring the effect of efficiency claims (the treatment) in merger litigation, the following is observed: $E\left(\mathrm{rem}_{s, t} \mid\right.$ eff $\left.=1\right)-E\left(\mathrm{rem}_{s, t} \mid\right.$ ef $\left.f=0\right)$, which is the difference in the outcome variables as a function of efficiency claims. Now denote the outcome of remedy size/timing by $\operatorname{rem}_{s, t}(1)$ for those mergers that reveal efficiency claims, and $\operatorname{rem}_{s, t}(0)$ for those individuals that do not. If only the treatment distinguishes the two groups, then the following equalities would hold:

$$
\begin{aligned}
& E\left[\operatorname{rem}_{s, t}(1) \mid \text { eff }=1\right]=E\left[\operatorname{rem}_{s, t}(0) \mid \text { eff }=1\right] \\
& E\left[\operatorname{rem}_{s, t}(0) \mid \text { eff }=0\right]=E\left[\text { rem }_{s, t}(1) \mid \text { eff }=0\right]
\end{aligned}
$$

Where $E\left[\right.$ rem $\left._{s, t}(1) \mid e f f=0\right]$ is the average remedy size/timing for mergers that reveal efficiency-evidence, had they not revealed this evidence, and $E\left[\right.$ rem $_{s, t}(1) \mid$ ef $f=$ $0]$ is the expected remedy size/timing for mergers that do not reveal evidence had they revealed this evidence. As $E\left[\operatorname{rem}_{s, t}(1) \mid e f f=0\right]$ and $E\left[\right.$ rem $_{s, t}(0) \mid$ eff $\left.=1\right]$ are

\footnotetext{
${ }^{38}$ To ensure that only valid effects are captured, only the two most frequently occurring industries were controlled for: manufacturing (60 cases), and energy (86 cases).
} 
Table 2: Summary statistics

\begin{tabular}{|c|c|c|c|c|}
\hline Variable & Description & $\begin{array}{l}\text { No saving } \\
\text { expectations } \\
(\mathrm{N}=97)\end{array}$ & $\begin{array}{l}\text { Saving } \\
\text { expectations } \\
(\mathrm{N}=117)\end{array}$ & $\begin{array}{l}\text { Total } \\
(\mathrm{N}=214)\end{array}$ \\
\hline phase & $\begin{array}{l}\text { Proportion of phase II } \\
\text { cases (binary) }\end{array}$ & $\begin{array}{c}0.392^{* * *} \\
(0.491)\end{array}$ & $\begin{array}{l}0.239^{* * *} \\
(0.429)\end{array}$ & $\begin{array}{l}0.308 \\
(0.463)\end{array}$ \\
\hline eff & $\begin{array}{l}\text { Efficiency revealed to } \\
\text { the Commission (binary) }\end{array}$ & $\begin{array}{l}0.113 \\
(0.319)\end{array}$ & $\begin{array}{l}0.128 \\
(0.336)\end{array}$ & $\begin{array}{l}0.121 \\
(0.327)\end{array}$ \\
\hline rem & $\begin{array}{l}\text { Timing of first remedy } \\
\text { offer }\end{array}$ & $\begin{array}{c}42.797 * * * \\
(34.813)\end{array}$ & $\begin{array}{l}30.388^{* * *} \\
(27.743)\end{array}$ & $\begin{array}{l}34.879 \\
(31.245)\end{array}$ \\
\hline rem 25 & $\begin{array}{l}\text { Remedy-offer before } \\
\text { day } 25 \text { (binary) }\end{array}$ & $\begin{array}{l}0.562^{* * *} \\
(0.500)\end{array}$ & $\begin{array}{l}0.735^{* * *} \\
(0.444)\end{array}$ & $\begin{array}{l}0.668 \\
(0.472)\end{array}$ \\
\hline remsize & $\begin{array}{l}\text { Time between first offer } \\
\text { and final decision }\end{array}$ & $\begin{array}{l}17.965 \\
(30.698)\end{array}$ & $\begin{array}{l}13.447 \\
(22.059)\end{array}$ & $\begin{array}{l}15.489 \\
(26.340)\end{array}$ \\
\hline$p a$ & $\begin{array}{l}\text { Value of the merger } \\
\text { transaction }\end{array}$ & $\begin{array}{l}1553^{* * *} \\
(2030)\end{array}$ & $\begin{array}{l}13150^{* * *} \\
(24232)\end{array}$ & $\begin{array}{l}7893 \\
(18844)\end{array}$ \\
\hline covlperc & $\begin{array}{l}\text { Market overlaps with } \\
\text { competitive concern }\end{array}$ & $\begin{array}{l}36.105 \\
(27.347)\end{array}$ & $\begin{array}{l}37.249 \\
(28.411)\end{array}$ & $\begin{array}{l}36.813 \\
(27.859)\end{array}$ \\
\hline vert & $\begin{array}{l}\text { Anticompetitive vertical } \\
\text { effects found (binary) }\end{array}$ & $\begin{array}{l}0.242^{*} \\
(0.434)\end{array}$ & $\begin{array}{l}0.162^{*} \\
(0.370)\end{array}$ & $\begin{array}{l}0.201 \\
(0.402)\end{array}$ \\
\hline coor & $\begin{array}{l}\text { Anticompetitive } \\
\text { coordinated effects (binary) }\end{array}$ & $\begin{array}{l}0.134 \\
(0.342)\end{array}$ & $\begin{array}{l}0.137 \\
(0.345)\end{array}$ & $\begin{array}{l}0.136 \\
(0.343)\end{array}$ \\
\hline startc 1 & $\begin{array}{l}\text { Notification within } 2 \text { months } \\
\text { after announcement (binary) }\end{array}$ & $\begin{array}{l}0.338 \\
(0.476)\end{array}$ & $\begin{array}{l}0.441 \\
(0.499)\end{array}$ & $\begin{array}{l}0.399 \\
(0.491)\end{array}$ \\
\hline startc 2 & $\begin{array}{l}\text { Notification } 2-4 \text { months } \\
\text { after announcement (binary) }\end{array}$ & $\begin{array}{l}0.325 \\
(0.471)\end{array}$ & $\begin{array}{l}0.405 \\
(0.493)\end{array}$ & $\begin{array}{l}0.372 \\
(0.485)\end{array}$ \\
\hline startc3 & $\begin{array}{l}\text { Notification later than } \\
4 \text { months (binary) }\end{array}$ & $\begin{array}{l}0.351^{* * *} \\
(0.480)\end{array}$ & $\begin{array}{l}0.162^{* * *} \\
(0.370)\end{array}$ & $\begin{array}{l}0.239 \\
(0.428)\end{array}$ \\
\hline$d i v$ & Divestiture remedy (binary) & $\begin{array}{l}0.396^{* * *} \\
(0.492)\end{array}$ & $\begin{array}{l}0.590^{* * *} \\
(0.494)\end{array}$ & $\begin{array}{l}0.502 \\
(0.501)\end{array}$ \\
\hline beh & Behavioural remedy (binary) & $\begin{array}{l}0.281^{* * *} \\
(0.452)\end{array}$ & $\begin{array}{l}0.103^{* * *} \\
(0.305)\end{array}$ & $\begin{array}{l}0.183 \\
(0.388)\end{array}$ \\
\hline divbeh & Divestiture + Behavioural (binary) & $\begin{array}{l}0.323 \\
(0.470)\end{array}$ & $\begin{array}{l}0.308 \\
(0.464)\end{array}$ & $\begin{array}{l}0.315 \\
(0.465)\end{array}$ \\
\hline
\end{tabular}


not observed, the equalities in Equation (4) are necessary to avoid bias. If Equation (4) does not hold, i.e. the treatment/no-treatment outcome (the timing and size of remedy-offer) is not the same for those treated and untreated (e.g. those that reveal and do not reveal efficiency-evidence to the Commission), then the LHS, which is observed, cannot be used as a reliable stand-in for the RHS, which is unobserved. In these cases the estimated difference between treated and not treated would be given by the average treatment effect on the treated plus a selection bias:

$$
\begin{aligned}
E\left[\operatorname{rem}_{s, t}(1) \mid e f f=1\right] & -E\left[\operatorname{rem}_{s, t}(0) \mid \text { eff }=0\right] \\
= & \left\{E\left[\operatorname{rem}_{s, t}(1) \mid \text { eff }=1\right]-E\left[\text { rem }_{s, t}(0) \mid \text { eff }=1\right]\right\} \\
+ & \left\{E\left[\operatorname{rem}_{s, t}(0) \mid \text { eff }=1\right]-E\left[\text { rem }_{s, t}(0) \mid \text { eff }=0\right]\right\}
\end{aligned}
$$

This would be the case if, for example, one was to believe that those mergers that reveal efficiency-evidence are less delay-averse. ${ }^{39}$ Because of this inherent difference in their attitude to delay, one could assume that these mergers are also more likely to offer smaller remedies upfront, causing the following (negative) selection bias:

$$
\begin{gathered}
E\left[\operatorname{rem}_{s}(0) \mid \text { eff }=1\right]<E\left[\operatorname{rem}_{s}(0) \mid \operatorname{eff}=0\right] \\
\Longrightarrow \quad E\left[\operatorname{rem}_{s}(0) \mid \text { eff }=1\right]-E\left[\operatorname{rem}_{s}(0) \mid \text { eff }=0\right]<0
\end{gathered}
$$

There are other reasons to believe that there may be a selection bias when analysing the determinants of remedy-size. As mentioned earlier, CT argues that more efficient mergers are less likely to offer large remedies, therefore if we accept that efficient mergers are the ones revealing efficiency-evidence, then OLS estimates will be negatively biased. To test whether single equation estimations provide unbiased results, a treatment effects (TE) model was run for the estimable equations in Table 1, the result of which is reported in Table 6 in the Appendix. The reported Wald test statistics imply that the null hypothesis of $\rho=0$ (i.e. that the estimated

\footnotetext{
${ }^{39}$ Because firms know that an efficiency claim leads to a lengthy delay.
} 
effect of treatment from single-equation OLS estimation is unbiased) can be rejected for Equation (2) but not for Equation (3). This provides evidence that OLS is biased for Equation (2), therefore a TE model is preferred in that case.

\subsection{Exogeneity of $v a l$ and $\mathbf{x}_{n}$}

The estimation of Equations (1)-(3) will be consistent only if none of the regressors are jointly determined with other observed or unobserved exogenous factors. Assumption 1 stated that $E\left(\mathbf{x}_{n}^{\prime} \varepsilon_{n}\right)=0$ and $E\left(v a l \varepsilon_{n}\right)=0$, i.e. unobserved shocks do not jointly determine val and $\mathbf{x}_{n}$ with the dependent variables. The problem with conducting a formal endogeneity test for $\mathbf{x}_{n}$, is the unavailability of data that would explain the variance in the elements of $\mathbf{x}_{n}$. However, White and Lu (2010) show that this is superfluous in a situation where we are only interested in estimating $\gamma_{n}$. In this case the weaker assumptions of:

$$
\begin{aligned}
& E\left(y_{n} \varepsilon_{n} \mid \mathbf{x}_{n}\right)=0, \text { and } \\
& E\left(\operatorname{val}_{n} \mid \mathbf{x}_{n}\right)=0
\end{aligned}
$$

should suffice, where $y_{i}$ denotes the causal - and potentially endogenous - variables, and $i=\left\{e f f, r e m_{s}\right\}$. This requires that elements of $\mathbf{x}_{n}$ are only predictive (and not causal) in their relationship to the dependent variable, which becomes clear once these elements are introduced in the estimations.

The exogeneity of saving expectations ( $\mathrm{val}$ ) cannot be formally verified within the scope of this paper as the necessary instruments are missing. However, intuition would tell us that the level of efficiency expectations signalled to shareholders are not jointly determined with the probability of making efficiency claims before the Commission or with the size and timing of the settlement offer. Efficiency signals to shareholders are very likely determined by firm and industry specific characteristics that affect the cost structure of firms. On the other hand, efficiency claims in litigation are probably strongly influenced by the way firms perceive the Commis-

sion's practice, or the litigation strategy proposed by their legal advisors. Regarding remedy offers, it is also more likely to be determined by and not determined with merger-generated cost savings. 


\subsection{Testing the endogeneity of $y_{i}$}

As the elements of firms' merger litigation strategy may be determined by the same unobserved factors (for example some measure of cost of delay, managerial opportunism, or the quality of the legal advisor), it is possible that there is an endogeneity problem in equations, where either eff or $\mathrm{rem}_{s}$ or both appear on the RHS of the estimable equations.

As endogeneity tests compare the efficiency and consistency of OLS and IV estimates, the elements of a vector of instruments $\left(\mathbf{z}_{n}\right)$ and exogenous variables for the structural equation $\left(\mathbf{x}_{n}\right)$ have to be chosen. Intuitively, efficiency claims $(e f f)$ may be affected by the observed factors of saving expectations signalled to shareholders or the amount of time firms prepare for filing a merger notification. The size of the remedy offer $\left(r e m_{s}\right)$ is expected to be influenced by observed variables such as efficiency claims in litigation, the complexity of the merger, or the type of remedy required by the Commission.

For the IV estimation the chosen instruments have to be valid and relevant. For the validity of instruments one needs the orthogonality assumption: $E\left(\mathbf{z}_{n}^{\prime} \varepsilon_{n}\right)=0$, and for the relevance: $E\left(\mathbf{z}_{n}^{\prime} y_{n} \mid \mathbf{x}_{n}\right) \neq 0$. To ensure that a unique solution exists, it is also assumed that $E\left(\mathbf{z}_{n}^{\prime} \mathbf{x}_{n}\right)$ has a full rank.

\subsection{Relevance of the instruments}

Hahn and Hausman (2003) show that weak (non-relevant) instruments mean that the bias from the IV estimators is the same or worse than the bias from using OLS, and therefore nothing is gained by using IV. ${ }^{40}$ Testing the relevance of instruments will be done by examining the fit of the reduced form (or first-stage) regressions. ${ }^{41}$ $R^{2}$ statistics to measure the partial effect of excluded instruments on the endogenous

\footnotetext{
${ }^{40}$ Staiger and Stock (1997) show that weak instruments lead to significant biases even in large samples.

${ }^{41}$ When eff appears as an endogenous regressor, its IV estimation could be done by using Equation (1) as a reduced form for $e f f$. Similarly, where $r e m_{s}$ is a potentially endogenous regressor, Equation (2) can be used as a reduced form.
} 
variable(s) as proposed by Bound et al. (1995) are used for this purpose. ${ }^{42}$ When there are two (or more) endogenous regressors, as in the case of Equation (3), then the effect of instruments should be partialled out for each of the endogenous variables. For this reason Shea's (1997) partial $R^{2}$ measure cases that takes the intercorrelations among the instruments into account is also made use of. Table 5 reports the $R^{2}$ 's for Equation (2) and Shea's partial $R^{2}$ 's for Equation (3) where the endogeneity of two variables is jointly tested. These measures conclude that the used instruments are sufficiently relevant. As a confirmation of this finding, the results of Anderson canonical correlation tests are also reported. ${ }^{43}$ The high Anderson test statistics (with a p-value of 0.062 in Equation (2) and 0.082 for Equation (3)) imply that the null (unidentified equation) can be rejected and the relevance of instruments is confirmed.

\subsection{Validity of the instruments}

As far as the validity of these instruments is concerned, it is a considerably more difficult issue as one would need to show that the instruments are not correlated with the error term in the structural equation. Tests, proposed by Sargan (1958) will be used to test validity, whereby the residuals from the 2SLS estimation are regressed on all exogenous (included and excluded) instruments. ${ }^{44}$ For orthogonality, the instruments should not have a significant effect on the residual. Assuming homoscedasticity, the Sargan test results reported in Table 5 imply that the nullhypothesis (i.e. that the instruments satisfy the orthogonality conditions) cannot be rejected in either Equation (2).

\footnotetext{
${ }^{42}$ More precisely, this method partials out the effect of the included instruments, by using the 'squarred partial correlation' between the excluded instruments $z_{1}$ and the endogenous regressor. It is defined by $\left(R S S_{z_{2}}-R S S_{z}\right) / T S S$, where $R S S_{z_{2}}$ is the $R S S$ of included instruments, and $R S S_{z}$ is the $R S S$ when all instruments are used.

${ }^{43}$ This test is based on the canonical correlation between two matrices, all exogenous variables, and the excluded exogenous variables. The null hypothesis of the Anderson test is that the smallest canonical correlation is zero, i.e. that the equations are not identified. For a discussion on Anderson's test see: Hall et al. (1996).

${ }^{44}$ As Davidson and MacKinnon (1993, pp. 235) shows Sargan's test uses an estimate of the error variance from the IV regression estimated with the full set of overidentifying restrictions.
} 
The non-i.i.d. errors in Equation (3) - tested later - justifies a different validity test. For this heteroscedastic case, a Hansen J-statistic is obtained based on Hansen (1982), which is probably the most frequently used measure of overidentification and validity in GMM estimation. ${ }^{45}$ A rejection of the null suggests that the orthogonality condition has been violated. The J-statistics are reported for the GMM regressions in Table 5 in the Appendix. The low figures, with a p-value of 0.9045 when Equation (3) allows for both eff and rems to be endogenous, and 0.592 when only $\mathrm{rem}_{s}$ is endogenous, imply that the null is not rejected.

The above tests provide sufficient evidence that the available instruments satisfy both the validity and relevance criteria. With these instruments in hand, Equations (2) and (3) were estimated using different IV methods. First, a 2SLS estimation was conducted, followed by a heeteroscedasticity test. Both the estimates and the teststatistics are reported in Table 5. Based on this, the homoscedasticity hypothesis was rejected for Equation (3). Hansen (1982) proposed that in this environment (i.e. unknown heteroscedasticity) the GMM estimates provide more efficient estimators, by making use of the orthogonality conditions. For this reason GMM estimates are also reported for Equation (3). ${ }^{46}$

\subsection{Testing endogeneity}

Although the use of instruments provides consistent estimates when $y_{n}$ is correlated with $\varepsilon_{n}$, it comes at the price of losing the efficiency of these estimates in comparison to OLS. Although this cost is worth bearing in situations where the OLS estimates would be biased but it would be a painful luxury if OLS also provides consistent estimates. For this reason, once valid and relevant instruments are found, the appropriateness of the OLS model was tested. For this reason the appropriateness of the OLS model was tested by comparing models using OLS and IV.

The Hausman test provides a measure that takes all regressors into account.

\footnotetext{
${ }^{45}$ The J-statistic equals the value of the GMM objective function evaluated at the efficient GMM estimators.

${ }^{46}$ Although one of the potentially endogenous variables is binary (eff), Wooldridge (2002) showed that there is no special consideration in using 2SLS or GMM when the endogenous variable is binary.
} 
For the purposes of this paper, however, the focus of interest is on two variables, eff and $\mathrm{rem}_{s}$, therefore a modified version of the above test is sufficient for testing only a subset of regressors for endogeneity. ${ }^{47}$ These test results (DWH-statistics in Table 5) report that the null hypothesis of exogeneity cannot be rejected for ef $f$ either in Equation (2) or (3). ${ }^{48}$ As far as $\mathrm{rem}_{s}$ is concerned, there is some very weak evidence of endogeneity in Equation (3) but only when eff was also treated as endogenous. When eff is treated as exogenous - for which there is evidence - then the exogeneity of $\mathrm{rem}_{s}$ cannot be rejected. This is probably due to the fact that the scope of instruments was limited in this research, therefore when both variables were assumed to be endogenous, the partial effect of these instruments on rems $_{s}$ (i.e. the effects not absorbed by eff) were such that exogeneity was rejected. As soon as all instruments were allocated solely to $\mathrm{rem}_{s}$, the test results changed.

To conclude this section, evidence was found for bias in the OLS estimation of Equation (2) and therefore a TE model is preferred in that case. To test endogeneity, a set of instruments were then tested and confirmed for validity and relevance, and were used for IV regressions, which allowed a comparison to OLS. No evidence for the endogeneity of the two regressors of interest ( $\mathrm{eff}$, and $r e m_{s}$ ) was found, therefore OLS provides consistent estimates for Equation (3). Nevertheless, one caveat still has to be made. Although the test results suggest that eff and $\mathrm{rem}_{s}$ is not endogenous, it is based on the available instruments. There may be other unobserved reasons why a firm reveals efficiency evidence, and therefore there is a chance that those that reveal this evidence are not randomly chosen.

\footnotetext{
${ }^{47}$ The main difference in this case is that, when the OLS and IV coefficient vectors are compared, the IV coefficients are obtained from a regression that assumes only a subset of regressors to be endogenous and the other are treated as exogenous.

${ }^{48}$ Hausman (1978)The test fits the model using both OLS and IV, and then compares the quadratic form of the coefficient vectors to decide whether the difference in the two estimation methods is given only by a loss in the efficiency of estimates, in which case OLS should be preferred.
} 


\subsection{The probit, TE, and OLS estimates for Equations (1)-(3)}

The results of the single-equation regressions, using probit for Equation (1) OLS and TE for (2) and OLS for (3), are reported in Table 3. Model a) controls for all available factors, whereas model b) only includes those that were significant in a). The table also reports the test-statistics (and p-values) of a Hausman test comapring models (a) and (b). For ease of reading, the hypotheses from Table 1 are inserted in the top rows.

\section{Discussion}

\subsection{The probability of efficiency claims - Hypothesis 1}

No evidence was found to reject the hypothesis that firms engage in mixed signalling. If firms' efficiency-related signals to shareholders are accepted as an adequate proxy for firms' true efficiency expectations, then this result implies that efficiency evidence is not revealed, even when available. A source of this discrepancy probably stems from the Commission's ambiguous treatment of efficiency claims. If one considers the Commission as a CA that commits to a rule that to some extent allows for efficiency defence - as proposed by LH - these results show that much of the efficiency related evidence is not extracted from mergers. This contradicts some assumptions that are often implicitly made in theoretical models of merger litigation, that is, mergers always reveal to the competition authority the efficiency gains they expect from the merger. $^{49}$

Another implication of the same finding is that there is no evidence to reject the hypothesis that some firms will apply for efficiency defence even when they themselves do not have such expectations, as is assumed by CT. This evidence adds to the findings of LH as well; committing to an enforcement rule that allows efficiency defence results in costs associated with rent seeking firms spending resources on forging false evidence.

\footnotetext{
${ }^{49}$ See for example: Motta and Vasconcelos (2005) or Neven and Röller (2005).
} 
Table 3: OLS estimates of Equations (1)-(3)

\begin{tabular}{|c|c|c|c|c|c|c|c|}
\hline \multirow{3}{*}{ Hypotheses } & \multirow{2}{*}{\multicolumn{2}{|c|}{$\begin{array}{c}\text { Probability of ED } \\
\text { H1: } \alpha_{v a l}=0\end{array}$}} & \multirow{2}{*}{\multicolumn{3}{|c|}{$\begin{array}{c}\text { Size of remedy } \\
\text { H2a: } \alpha_{\text {val }}>0 \\
\text { H3: } \gamma_{\text {eff }}=0\end{array}$}} & \multirow{2}{*}{\multicolumn{2}{|c|}{$\begin{array}{c}\text { Timing of offer } \\
\text { H2b: } \alpha_{\text {val }}<0 \\
\text { H3: } \gamma_{\text {eff }}=0 \\
\text { H4: } \gamma_{\text {rems }}>0\end{array}$}} \\
\hline & & & & & & & \\
\hline & $\begin{array}{c}\text { (a) } \\
\text { probit }\end{array}$ & $\begin{array}{l}\text { (b) } \\
\text { probit }\end{array}$ & $\begin{array}{l}\text { (a) } \\
\text { OLS }\end{array}$ & $\begin{array}{l}\text { (b) } \\
\text { OLS }\end{array}$ & $\mathrm{TE}$ & $\begin{array}{l}\text { (a) } \\
\text { OLS }\end{array}$ & $\begin{array}{l}\text { (b) } \\
\text { OLS }\end{array}$ \\
\hline val & $\begin{array}{l}-1.079 \\
(0.973)\end{array}$ & & $\begin{array}{l}9.549^{*} \\
(5.526)\end{array}$ & $\begin{array}{l}10.958^{*} \\
(5.591)\end{array}$ & $\begin{array}{l}10.975 \\
(7.111)\end{array}$ & $\begin{array}{c}-18.017^{* *} \\
(7.298)\end{array}$ & $\begin{array}{c}-19.440^{* *} \\
(7.729)\end{array}$ \\
\hline $\begin{array}{l}\text { eff } \\
\text { remsize }\end{array}$ & & & $\begin{array}{l}-4.027 \\
(8.213)\end{array}$ & $\begin{array}{l}-2.838 \\
(8.197)\end{array}$ & $\begin{array}{c}-46.821^{* * *} \\
(12.807)\end{array}$ & $\begin{array}{c}32.451^{* * *} \\
(9.569) \\
0.266^{* *} \\
(0.120)\end{array}$ & $\begin{array}{c}29.372^{* * *} \\
(9.479) \\
0.292^{* * *} \\
(0.110)\end{array}$ \\
\hline $\mathrm{val}^{*} \mathrm{eff}$ & & & $\begin{array}{c}-113.070^{* * *} \\
(29.942)\end{array}$ & $\begin{array}{c}-114.941^{* * *} \\
(27.462)\end{array}$ & $\begin{array}{c}-122.250^{* * *} \\
(26.227)\end{array}$ & $\begin{array}{c}-87.797^{* * * *} \\
(32.177)\end{array}$ & $\begin{array}{c}-76.417^{* *} \\
(34.981)\end{array}$ \\
\hline $\begin{array}{l}\text { ecmr } \\
\text { remsize*ecmr }\end{array}$ & $\begin{array}{c}0.393 \\
(0.289)\end{array}$ & & $\begin{array}{l}-7.102 \\
(5.375)\end{array}$ & $\begin{array}{l}-7.108 \\
(4.773)\end{array}$ & $\begin{array}{l}-9.592^{*} \\
(5.421)\end{array}$ & $\begin{array}{c}-12.924^{* *} \\
(5.388) \\
-0.255^{*} \\
(0.143)\end{array}$ & $\begin{array}{c}-15.867^{* * *} \\
(5.551) \\
-0.299^{* *} \\
(0.134)\end{array}$ \\
\hline ovlperc & $\begin{array}{c}0.007 \\
(0.006)\end{array}$ & $\begin{array}{c}0.002 \\
(0.006)\end{array}$ & $\begin{array}{c}-0.315^{* * *} \\
(0.119)\end{array}$ & $\begin{array}{c}-0.311^{* * *} \\
(0.107)\end{array}$ & $\begin{array}{c}-0.283^{* *} \\
(0.134)\end{array}$ & $\begin{array}{c}0.201 \\
(0.125)\end{array}$ & $\begin{array}{c}0.181 \\
(0.123)\end{array}$ \\
\hline vert & $\begin{array}{l}-0.064 \\
(0.536)\end{array}$ & $\begin{array}{c}-0.232 \\
(0.521)\end{array}$ & $\begin{array}{l}-7.388 \\
(6.667)\end{array}$ & $\begin{array}{l}-5.934 \\
(6.364)\end{array}$ & $\begin{array}{l}-7.244 \\
(8.054)\end{array}$ & $\begin{array}{c}4.889 \\
(8.160)\end{array}$ & $\begin{array}{c}3.369 \\
(8.104)\end{array}$ \\
\hline coor & $\begin{array}{c}0.840 \\
(0.565)\end{array}$ & $\begin{array}{l}0.837^{*} \\
(0.476)\end{array}$ & $\begin{array}{c}-7.385 \\
(10.837)\end{array}$ & $\begin{array}{c}-7.262 \\
(10.041)\end{array}$ & $\begin{array}{c}1.882 \\
(12.612)\end{array}$ & $\begin{array}{l}-13.082 \\
(12.661)\end{array}$ & $\begin{array}{l}-14.365 \\
(12.666)\end{array}$ \\
\hline ovlperc* ${ }^{*}$ coor & $\begin{array}{c}0.002 \\
(0.008)\end{array}$ & $\begin{array}{c}0.003 \\
(0.008)\end{array}$ & $\begin{array}{c}0.085 \\
(0.185)\end{array}$ & $\begin{array}{c}0.083 \\
(0.179)\end{array}$ & $\begin{array}{c}0.070 \\
(0.216)\end{array}$ & $\begin{array}{c}0.050 \\
(0.214)\end{array}$ & $\begin{array}{c}0.046 \\
(0.205)\end{array}$ \\
\hline ovlperc* vert & $\begin{array}{c}0.006 \\
(0.011)\end{array}$ & $\begin{array}{c}0.004 \\
(0.010)\end{array}$ & $\begin{array}{c}0.240 \\
(0.158)\end{array}$ & $\begin{array}{c}0.230 \\
(0.150)\end{array}$ & $\begin{array}{c}0.349 \\
(0.263)\end{array}$ & $\begin{array}{l}0.422^{*} \\
(0.243)\end{array}$ & $\begin{array}{c}0.373 \\
(0.248)\end{array}$ \\
\hline behavioural & & & $\begin{array}{c}3.895 \\
(5.088)\end{array}$ & & & $\begin{array}{c}12.244^{* *} \\
(5.922)\end{array}$ & $\begin{array}{c}14.102^{* *} \\
(5.881)\end{array}$ \\
\hline $\operatorname{div}+$ beh & & & $\begin{array}{c}0.956 \\
(5.201)\end{array}$ & & & $\begin{array}{c}17.273^{* * *} \\
(5.729)\end{array}$ & $\begin{array}{c}19.636^{* * *} \\
(5.921)\end{array}$ \\
\hline startc2 & $\begin{array}{l}-0.285 \\
(0.354)\end{array}$ & $\begin{array}{l}-0.073 \\
(0.342)\end{array}$ & & & & & \\
\hline startc3 & $\begin{array}{c}0.722^{* *} \\
(0.329)\end{array}$ & $\begin{array}{c}0.549^{* * *} \\
(0.287)\end{array}$ & & & & & \\
\hline manufacturing & $\begin{array}{l}0.697^{*} \\
(0.358)\end{array}$ & $\begin{array}{l}0.481^{*} \\
(0.267)\end{array}$ & $\begin{array}{l}1.747 \\
(4.884)\end{array}$ & & & $\begin{array}{l}-6.704 \\
(5.930)\end{array}$ & \\
\hline energy & $\begin{array}{c}0.036 \\
(0.365)\end{array}$ & & $\begin{array}{l}-2.705 \\
(4.152)\end{array}$ & & & $\begin{array}{l}-3.312 \\
(5.525)\end{array}$ & \\
\hline padsim & $\begin{array}{l}-0.000 \\
(0.000)\end{array}$ & & $\begin{array}{c}0.000 \\
(0.000)\end{array}$ & & & $\begin{array}{l}-0.000 \\
(0.000)\end{array}$ & \\
\hline cons & $\begin{array}{c}-2.019^{* * *} \\
(0.527)\end{array}$ & $\begin{array}{c}-1.789 * * * \\
(0.331)\end{array}$ & $\begin{array}{l}-9.505^{*} \\
(5.372)\end{array}$ & $\begin{array}{c}-9.868^{* *} \\
(4.291)\end{array}$ & $\begin{array}{l}-5.189 \\
(5.786)\end{array}$ & $\begin{array}{c}30.589^{* * *} \\
(7.351)\end{array}$ & $\begin{array}{c}29.662^{* * *} \\
(6.078)\end{array}$ \\
\hline $\begin{array}{l}\mathrm{R}^{2} \\
\text { Quasi } \mathrm{R}^{2}\end{array}$ & 0.205 & 0.203 & 0.175 & 0.171 & & 0.338 & 0.310 \\
\hline $\begin{array}{l}\text { Hausman Chi2 } \\
\text { (p-value) }\end{array}$ & $\begin{array}{l}1 . \\
(0 .\end{array}$ & & $(0$. & & & $\begin{array}{r}1 . \\
1 .\end{array}$ & \\
\hline
\end{tabular}

*** significant at $0.01,{ }^{* *}$ significant at $0.05,{ }^{*}$ significant at 0.1

standard errors between brackets 
On more of a side note, an interesting finding is that given the other regressors, the ECMR reform in 2004 did not have an effect on the probability of efficiency arguments in the Commission's case reports, which is very peculiar given that one of the most often cited elements of the ECMR reform was the change in the attitude towards efficiency related evidence. This is probably due to the fact that post-2004 efficiency claims were still treated inauspiciously by the Commission and therefore the attitude of merging parties and their legal advisors toward efficiency claims did not change significantly.

Some evidence was also found that long preparation for the merger application increases the probability of making efficiency claims before the Commission. As firms and their legal advisors are certainly aware of the fact that efficiency claims typically lead to lengthy investigations, mergers with lower cost of delay are more likely to make efficiency claims before the Commission. Long delays pre-notification may be a sign of lesser delay-averseness or lower delay costs.

\subsection{Seeking early settlement - Hypothesis 2}

Table 4 summarises the effect of efficiency claims on remedy size and timing, based on the coefficients of eff, val, and val *eff. Signs show the estimates from the consistent model, signs in the bracket show the OLS estimates. The rankings are based on the estimates in Table 3 ( 1 denoting the largest and earliest remedy offer).

Table 4: Sign of the effect of synergy gains on remedy-offers

Remedy offer

\begin{tabular}{ccccccc} 
& & \multicolumn{2}{c}{ Size } & \multicolumn{2}{c}{ Timing } \\
\hline & & & sign & rank & sign & rank \\
\hline \multirow{2}{*}{$\begin{array}{c}\text { Efficiency } \\
\text { No evidence }\end{array}$} & No bluff & baseline & 2 & baseline & 3 \\
\cline { 2 - 6 } & Evidence & Bluff & $-(0)$ & 3 & $+(+)$ & 4 \\
\cline { 2 - 6 } & & Reveal & $-(-)$ & 4 & $-(-)$ & 1 \\
& & Withold & $0(+)$ & 1 & $-(-)$ & 2
\end{tabular}

Table 4 distinguishes between two main groups of cases, ones that have efficiency expectations, and ones without such expectations. As was shown above, belonging 
to either of these groups does not have an effect on whether firms make efficiency claims to the Commission. Some firms make false efficiency claims, and some of them withhold the evidence even if they have it, which is also shown in the table. The sign of the estimates show that firms that bluff in their efficiency claims make smaller and delayed remedy-offers. The effect of synergy expectations on the relative size of the remedy-offer depends on whether parties reveal efficieny-related evidence to the Commission. When efficiency-evidence is revealed then the more efficient they think their merger will be, the smaller remedy-offer firms are going to make. This is in line with CT, who argue that efficient mergers value their assets higher and are therefore less willing to sell these assets as part of their settlement (divestiture remedy). The curious thing however is that this relationship only exists if firms revealed their efficiency expectations to the Commission. An intuitive explanation may be that only those mergers will resort to efficiency defence that are less delay-averse. ${ }^{50}$ For mergers where cost of delay exceeds cost of divestiture, firms become more eager to seek a suitable settlement. ${ }^{51}$ The fact that efficiency claims are made implies reduced delay-averseness. In these cases the perceived cost of delay is probably smaller, and therefore other motivations may dominate, such as the one highlighted by CT. What this means for $\mathrm{CT}$ is that accounting for cost of delay could rewrite their results, and firms, whose delay-costs exceed the loss experienced by asset divestiture may have an incentive to make larger remedy-offers.

Tests on treatment effects provided evidence that firms that reveal efficiencyrelated evidence are inherently different in the size of their remedy-offer. This is potentially caused by the inherent difference between the cost of delay of firms that apply for efficiency defence and firms that do not. This is confirmed by Table 4, which shows that firms with potentially the highest cost of delay (have evidence but withheld) offer larger and earlier remedies. Firms with revealed evidence are

\footnotetext{
${ }^{50}$ Mergers that lose more with a delay are typically better at making sure that their litigation strategy results in earlier approval and are therefore ready to making an early and suitable settlement offer.

${ }^{51}$ This effect is further mitigated by the fact that in these cases shareholders have a higher expectation about the synergies to be realised. A delay in these cases would probably strongly decrease the shareholder evaluation of the merger, something that most managers would be eager to avoid.
} 
expected to be less delay-averse because they have engaged in a lengthy efficiency defence. These mergers offer the smallest but earliest remedies. This may be because they are bluffing in their remedy-offer (as claimed in GL), or because they value their efficient assets mode (as argued by $\mathrm{CT}$ ), or because they try to tailor their remedy offers to take efficiency gains into account, as proposed by Röller and de la Mano (2006). Those firms that bluff in their efficiency claims make smaller and more delayed remedy-offers suggesting the lowest costs of delay.

Hypothesis $2 \mathrm{~b}$ cannot be rejected either. High saving expectations signalled to shareholders imply earlier settlement offers. Table 4 shows that cases differ depending on whether efficiency claims have been made to the Commission. There is evidence in general that settlement offers are made earlier as efficiency expectations increase. However, this effect is significantly stronger in cases where efficiency evidence is revealed. Cost of delay may provide an explanation to this result as well. Firms revealing efficiency evidence to the Commission are less delay-averse, and could therefore be bluffing in the remedy-offer. As bluffing always has a risk of failure, these mergers make early offers to allow themselves enough time to readjust their offer in case their bluff has been detected. ${ }^{52}$ This is confirmed by testing Hypothesis 4 . Table 3 provides evidence that smaller remedies are more likely to be offered earlier, which corresponds to the bluffing strategy suggested by GL. Although this effect was strongly present under the old-ECMR, it has significantly diminshed after the 2004 ECMR reform, not because less firms try to bluff, but because in recent years remedy-offers in general are all made early in the litigation.

Table 4 also reveals that a clear indicator that distinguishes genuine efficiency claims from bluffs is the timing of the remedy offer. Firms that bluff in their efficiency claims make significantly delayed remedy-offers.

\footnotetext{
${ }^{52}$ To put it differently, assuming that firms follow the Commission's practice, they must be aware of the fact the efficiency claims are likely to result in phase II investigations. Because of this they are in no hurry to offer an early remedy unless they want the Commission to ignore the efficiency claims and approve the merger solely based on the remedy offers. (As happened in Case COMP/M.3099 Areva/Urenco (2004); and in Case No COMP/M.4000 - Inco/Falconbridge (2006).) The evidence found here suggests that once parties reveal their efficiency expectations to the Commission they wait with their remedy offer until the Commission decides on whether to accept the efficiency claim or not, and offer their remedy subsequently if it is still needed.
} 


\subsection{Effect of efficiency claims - Hypothesis 3}

Röller and de la Mano (2006) pointed out the importance of the Commission tailoring remedies to take available efficiencies into account. The purpose of this hypothesis was to test the attitude of merging parties to this issue. As partly discussed above, the coefficient of eff shows that efficiency claims always reduce the size of the first remedy-offer. Again, this may be for a mixture of reasons, one of them is that firms may indeed try to reduce the size of their remedy-offers in order to reflect potential efficiency gains once these gains are known to the Commission (otherwise it would be pointless, as without the efficiency claim, the Commission would have no efficiency-evidence that could support a reduction in the size of remedy).

An interesting finding is that once we control other factors the estimations did not find evidence that the complexity of the merger has an effect on the timing of the first remedy offer. This implies that parties decide on when to make offers, irrespective of the complexity (as measured by the number of overlaps and vertical or coordinated effects) of the case, therefore a merger with numerous concerned overlaps is no more likely to be ready to make early offers as a merger with only vertical effects.

\section{Robustness checks}

The robustness and validity of Assumption 1 was discussed in Section 5.2 therefore only the remaining assumptions are examined here.

Assumption 2 stated that firms first decide on whether to reveal efficiency claims and then define their settlement offer. This assumption is based on the fact that the EC encourages merging parties to reveal efficiency claims in the pre-notification stage of the procedure. Also, efficiencies are assessed as part of the competitive analysis in EC merger procedures. This means that the Commission requires remedies only after the harm has been established, i.e. when merger-generated gains have already been taken into account. Nevertheless, if the size of the remedy or the timing of the remedy-offer had a causal effect on revealing efficiency claims before the Commission (i.e. if $\gamma_{11} \neq 0$ or $\gamma_{12} \neq 0$ ), then the system could be estimated following Keshk (2003) 
based on Maddala (1983). Using the same variables as in the OLS estimation, the results thereby acquired show that none of the regressors have any impact on the dependent variables. As this contradicts the strong correlation between some of the variables, this possibility was rejected and Assumption 2 was maintained.

Assumptions $\mathbf{3 a}, \mathbf{3} \mathbf{b}$ are about the pairwise independence of the error terms in Equations (1) and (2) and Equations (1) and (3). Although a formal test cannot be conducted to verify this assumption, intuition provides some guidance. This assumption means that the unobserved parts of the variance of the respective dependent variables are determined by the same unobserved factors. Intuitively, whether firms reveal efficiency-related evidence to the Commission is more likely to be influenced by the way firms perceive the Commission's practice, or the litigation strategy proposed by their legal advisors. Settlement (remedy) offers on the other hand are probably determined by various characteristics (such as profitability) of the divestible assets that are offered in settlements.

Finally, Assumption 4 introduces a one-way causality between the relative size of the remedy-offer and the timing of this offer. One alternative scenario would be, where neither $\gamma_{22}$ nor $\gamma_{32}$ equals zero (i.e. $r e m_{s}$ causes rem $r_{t}$ and vice versa), which would result in a system of simultaneous equations, that could be estimated using a two-stage or an instrumental variable method. The key question is what sort of prior can be brought into the estimation based on theory. Based on the discussion in Section 3.2, it is unlikely that firms first decide on the timing of the offer and then set the size of the offer, therefore two-way cusality can be excluded.

Another alternative would be where neither of the dependent variables in Equations (2) and (3) appear on the RHS of these equations. This would mean that the correlation between $\mathrm{rem}_{s}$ and $\mathrm{rem}_{t}$ reflects a purely predictive and not causal relationship. In the absence of such a causality (i.e. if $\gamma_{22}=\gamma_{32}=0$ ), Equations (2) and (3) could be estimated by either OLS or, if $\operatorname{corr}\left(\varepsilon_{2}, \varepsilon_{3}\right) \neq 0$ then a seemingly unrelated regression can be used as explained in Zellner (1962). To verify that this is not the case, the estimates of a seemingly unrelated regression are presented in Table 7 in the Appendix. The small Breusch-Pagan test statistics suggest that the null-hypothesis of independent rems and remt (more precisely independent residuals 
from the two equations) cannot be rejected, and therefore the OLS estimates are preferred.

\section{Conclusion}

The paper gave an empirical analysis of merging firms' litigation strategy. It was shown that the current EC merger control regime is incapable of extracting information from firms on their efficiency expectations. Firms that expect their merger to generate efficiency gains are more likely to make upfront remedy-offers. Efficiency claims (valid or false) made to the Commission reduce the size of the remedy-offer, however false efficiency claims can be distinguished by looking at the timing of the remedy-offer. Cost of delay plays a central role in designing firms' litigation strategy, especially when these costs exceed the cost of the remedy.

The paper raises a few questions to the policymaker. Firstly, given the potential for rent seeking that results in forging false efficiency evidence, it should be considered whether a procedural fine should be introduced for providing false efficiency-evidence. Secondly, the current practice of phase I and phase II investigations means that even efficient firms refrain from making efficiency claims and they offer remedies instead, leading to potential type I errors in EC merger control. And finally, better incentives to reveal efficiency-evidence should be introduced, for example by requiring the Commission to make sure that remedies are tailored to take efficiency-gains into account.

\section{A Tables and estimates}


Table 5: 2SLS and GMM regressions and endogeneity tests

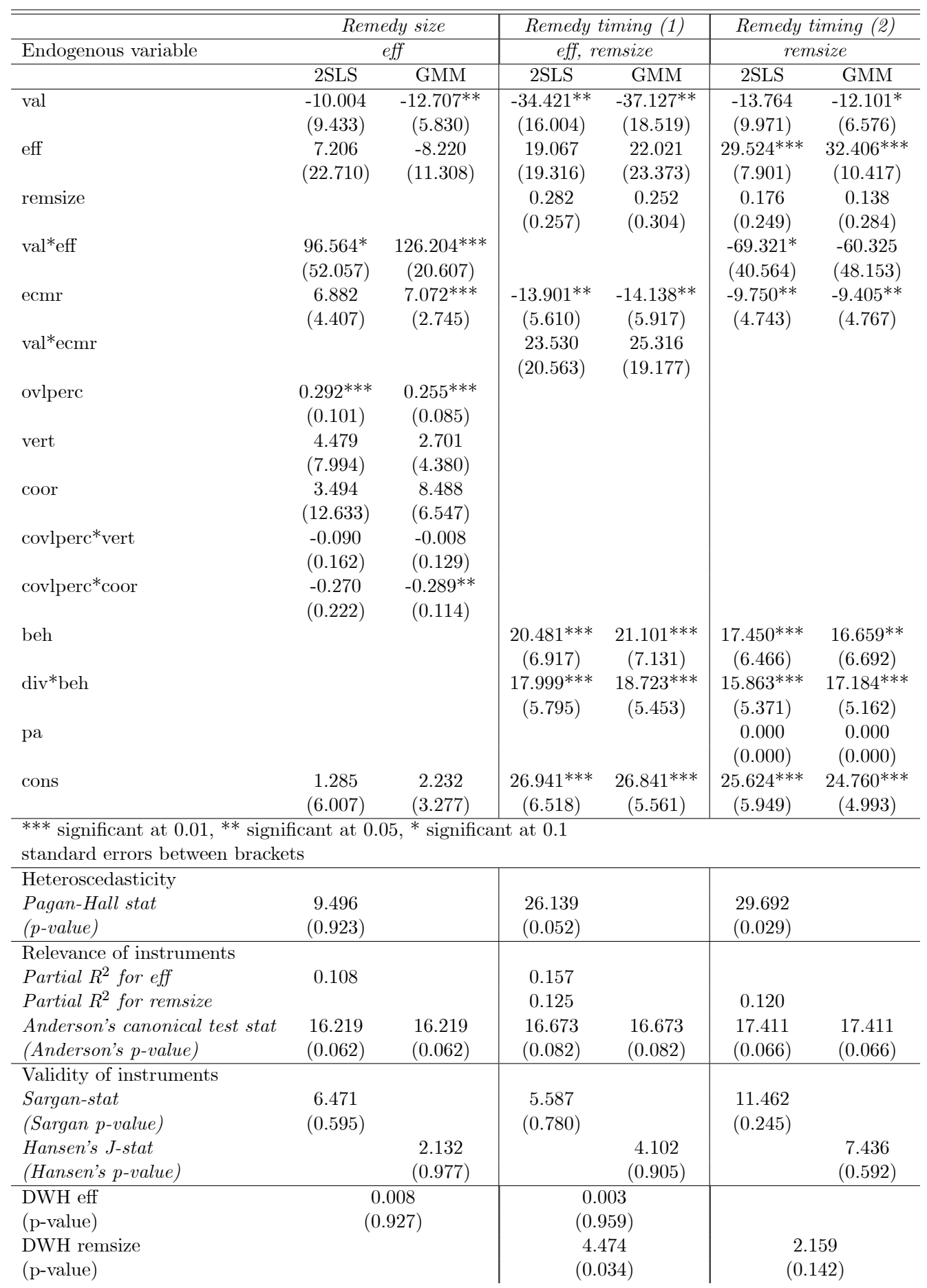


Table 6: Treatment effects models

\begin{tabular}{|c|c|c|}
\hline & Remedy size & Remedy timing \\
\hline Treatment variable & eff & eff \\
\hline val & $\begin{array}{l}10.975 \\
(7.111)\end{array}$ & $\begin{array}{c}-15.115^{* *} \\
(6.900)\end{array}$ \\
\hline eff & $\begin{array}{c}-46.821^{* * *} \\
(12.807)\end{array}$ & $\begin{array}{c}29.241^{* *} \\
(14.594)\end{array}$ \\
\hline remsize & & $\begin{array}{c}0.245^{* *} \\
(0.103)\end{array}$ \\
\hline val $^{*}$ eff & $\begin{array}{c}-122.250^{* * *} \\
(26.227)\end{array}$ & $\begin{array}{c}-77.476^{* *} \\
(36.261)\end{array}$ \\
\hline ecmr & $\begin{array}{l}-9.592^{*} \\
(5.421)\end{array}$ & $\begin{array}{c}-10.205^{*} \\
(5.307)\end{array}$ \\
\hline remsize*ecmr & & $\begin{array}{c}-0.242^{*} \\
(0.128)\end{array}$ \\
\hline ovlperc & $\begin{array}{c}-0.283^{* *} \\
(0.134)\end{array}$ & $\begin{array}{c}0.122 \\
(0.120)\end{array}$ \\
\hline vert & $\begin{array}{l}-7.244 \\
(8.054)\end{array}$ & $\begin{array}{c}6.420 \\
(8.458)\end{array}$ \\
\hline coor & $\begin{array}{c}1.882 \\
(12.612)\end{array}$ & $\begin{array}{c}-9.094 \\
(12.466)\end{array}$ \\
\hline ovlperc* vert & $\begin{array}{c}0.070 \\
(0.216)\end{array}$ & $\begin{array}{c}0.127 \\
(0.202)\end{array}$ \\
\hline ovlperc $^{*}$ coor & $\begin{array}{c}0.349 \\
(0.263)\end{array}$ & $\begin{array}{c}0.321 \\
(0.276)\end{array}$ \\
\hline beh & & $\begin{array}{c}12.244^{* *} \\
(5.757)\end{array}$ \\
\hline div*beh & & $\begin{array}{l}12.074^{*} \\
(6.241)\end{array}$ \\
\hline cons & $\begin{array}{l}-5.189 \\
(5.786)\end{array}$ & $\begin{array}{c}27.141^{* * *} \\
(5.886)\end{array}$ \\
\hline \multicolumn{3}{|c|}{ Effect on treatment variable $($ eff $)$} \\
\hline ovlperc & $\begin{array}{c}0.002 \\
(0.006)\end{array}$ & $\begin{array}{c}0.004 \\
(0.007)\end{array}$ \\
\hline vert & $\begin{array}{l}-0.213 \\
(0.508)\end{array}$ & $\begin{array}{l}-0.062 \\
(0.543)\end{array}$ \\
\hline coor & $\begin{array}{l}1.253^{* *} \\
(0.496)\end{array}$ & $\begin{array}{l}0.932^{*} \\
(0.562)\end{array}$ \\
\hline covlperc $^{*}$ vert & $\begin{array}{l}-0.000 \\
(0.010)\end{array}$ & $\begin{array}{l}-0.002 \\
(0.009)\end{array}$ \\
\hline covlperc*coor & $\begin{array}{l}-0.001 \\
(0.010)\end{array}$ & $\begin{array}{c}0.001 \\
(0.012)\end{array}$ \\
\hline startc2 & $\begin{array}{c}0.007 \\
(0.214)\end{array}$ & $\begin{array}{l}-0.113 \\
(0.359)\end{array}$ \\
\hline startc3 & $\begin{array}{c}0.691^{* *} \\
(0.281)\end{array}$ & $\begin{array}{l}0.614^{*} \\
(0.337)\end{array}$ \\
\hline manufacturing & $\begin{array}{l}0.497^{*} \\
(0.269)\end{array}$ & $\begin{array}{c}0.670^{* *} \\
(0.300)\end{array}$ \\
\hline cons & $\begin{array}{c}-1.540^{* * *} \\
(0.392)\end{array}$ & $\begin{array}{c}-1.766^{* * *} \\
(0.356)\end{array}$ \\
\hline $\begin{array}{l}* * * \text { significant at } 0.01,{ }^{* *} \\
\text { standard errors between br }\end{array}$ & $\begin{array}{l}\text { nificant at } 0 \\
\text { kets }\end{array}$ & significant at \\
\hline Rho & $1.338^{* * *}$ & 0.091 \\
\hline lnsigma & $3.450^{* * *}$ & $3.217^{* * *}$ \\
\hline $\begin{array}{l}\text { Wald test of independence } \\
\text { (p-value) }\end{array}$ & $\begin{array}{l}14.551 \\
(0.001)\end{array}$ & $\begin{array}{c}0.172 \\
(0.678)\end{array}$ \\
\hline
\end{tabular}


Table 7: Zellner's seemingly unrelated regression

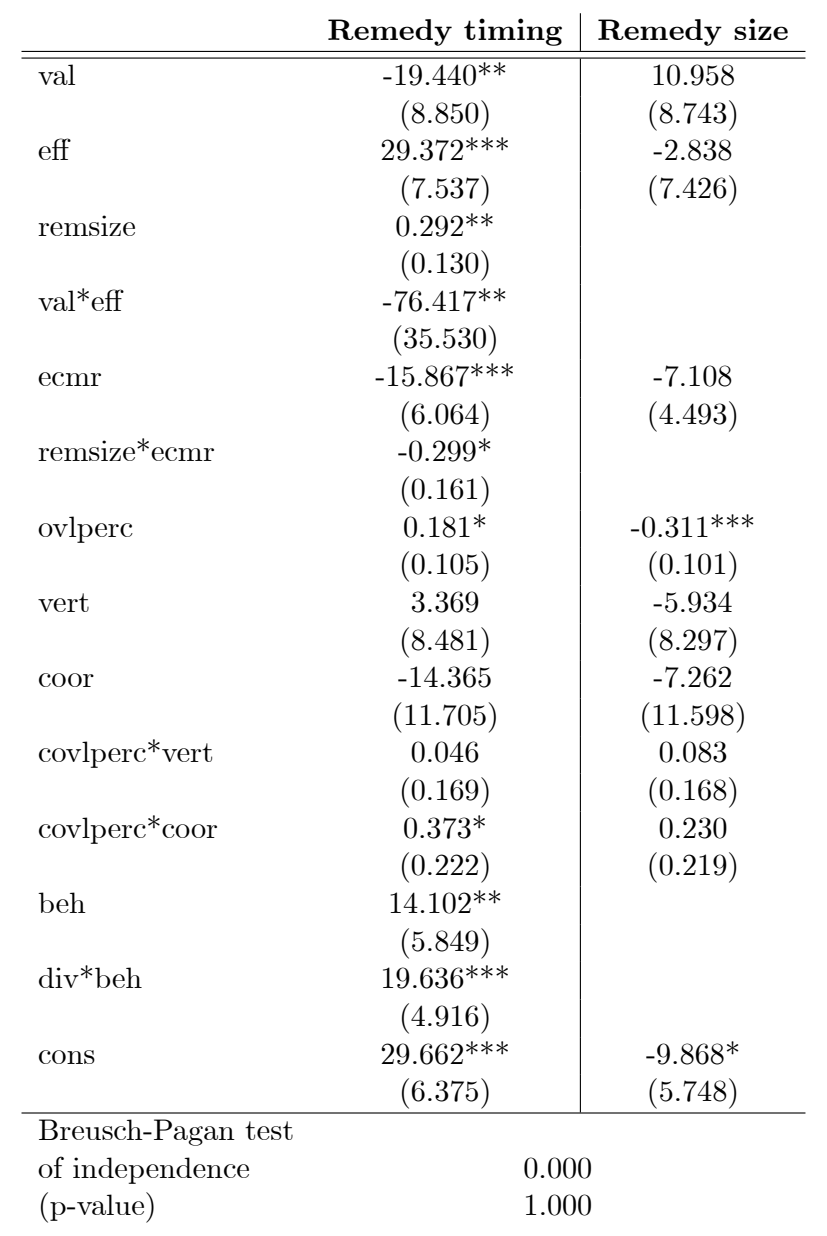




\section{References}

Bergman, M., Coate, M. B., Jakobsson, M., Ulrick, S. W., 2007. Comparing merger policies: The european union versus the united states. Available at SSRN: http://ssrn.com/abstract $=975102$.

Bhagat, S., Brickley, J. A., Coles, J. L., 1994. The costs of inefficient bargaining and financial distress: Evidence from corporate lawsuits. Journal of Financial Economics 35 (2), 221-247.

Bhagat, S., Romano, R., 2002. Event studies and the law - part i: Technique and corporate litigation. American Law and Economics Review 4 (1), 141-167.

Bougette, P., 2010. Preventing merger unilateral effects: A nash cournot approach to asset divestitures. Research in Economics 64, 162-174.

Bougette, P., Turolla, S., 2006. Merger remedies at the european commission: A multinomial logit analysis. Available at: http://mpra.ub.uni-muenchen.de/2461/.

Bound, J., Jaeger, D. A., Baker, R. M., 1995. Problems with instrumental variables estimation when the correlation between the instruments and the endogeneous explanatory variable is weak. Journal of the American Statistical Association 90 (430), 443-450.

Breen, R., 1996. Regression Models: Censored, Sample Selected, or Truncated Data (Quantitative Applications in the Social Sciences). Sage Publications.

Chang, P. C., 1988. A measure of the synergy in mergers under a competitive market for corporate control. Atlantic Economic Journal 16 (2), 59-62.

Chanmugam, R., Shill, W., Mann, D., Ficery, K., Pursche, B., 2005. The intelligent clean room: Ensuring value capture in mergers and acquisitions. Journal of Business Strategy 26 (3), 43-49.

Cosnita, A., Tropeano, J.-P., 2009. Negotiating remedies: Revealing the merger efficiency gains. International Journal of Industrial Organization 27, 188-196. 
Davidson, R., MacKinnon, J. G., 1993. Estimation and Inference in Econometrics, 2nd Edition. Oxford University Press., New York.

Epstein, M. J., 2004. The drivers of success in post-merger integration. Organizational Dynamics 33 (2), 174-189.

Fields, M. A., 1990. The wealth effects of corporate lawsuits: Pennzoil v. texaco. Journal of Business Research 21 (2), 143-158.

Garrod, L., Lyons, B., 2011. Early settlement and errors in merger control. CCP Working Paper 11-5.

Hahn, J., Hausman, J., 2003. A new specification test for the validity of instrumental variables. Econometrica 70 (1), 163-189.

Hall, A., Rudebusch, G. D., Wilcox, D. W., 1996. Judging instrument relevance in instrumental variables estimation. International Economic Review 37 (2), 283-98.

Hansen, J., 1982. Large sample properties of generalized method of moments estimators. Econometrica 50 (3), 1029-1054.

Hausman, J. A., 1978. Specification tests in econometrics. Econometrica 46 (6), 12511271.

Keshk, O. M. G., 2003. Cdsimeq: A program to implement two-stage probit least squares. The Stata Journal 3 (2), 157-167.

Koku, P. S., Qureshi, A. A., 2006. Analysis of the effects of settlement of interfirm lawsuits. Managerial and Decision Economics 27 (4), 307-318.

Lagerlöf, J. N., Heidhues, P., 2005. On the desirability of an efficiency defense in merger control. International Journal of Industrial Organiyation 23, 803-827.

Maddala, G. S., 1983. Limited-Dependent and Qualitative Variables in Econometrics. Cambridge University Press, Cambridge. 
Maddala, G. S., Lee, L.-F., 1976. Recursive models with qualitative endogenous variables. Annals of Economic and Social Measurement 5 (4), 168-188.

Motta, M., Vasconcelos, H., 2005. Efficiency gains and myopic antitrust authority in a dynamic merger game. International Journal of Industrial Organization 23, $777-801$.

Neven, D. J., Röller, L.-H., December 2005. Consumer surplus vs. welfare standard in apolitical economy model of merger control. International Journal of Industrial Organization 23 (9-10), 829-848.

Röller, L.-H., de la Mano, M., 22 January 2006. The impact of the new substantive testin european merger control. European Commission.

Sargan, J. D., 1958. The estimation of economic rela-tionships using instrumental variables. Econometrica 26, 393-415.

Shea, J., 1997. Instrument relevance in multivariate linear models: A simple measure. The Review of Economics and Statistics 79 (2), 348-352.

Staiger, D., Stock, J. H., 1997. Instrumental variables regression with weak instruments. Econometrica 65 (3), 557-586.

White, H., Lu, X., 2010. Robustness checks and robustness tests in applied economics. Working Paper, Department of Economics, University of California.

Wooldridge, J., 2002. Econometric Analysis of Cross Section and Panel Data. Massachusetts Institute of Technology.

Zellner, A., 1962. An efficient method of estimating seemingly unrelated regressions and tests for aggregation bias. Journal of the American Statistical Association 57 (298), 348-368. 